mineral particles that lie deeper than half a mile below the land surface, and therefore unavailable. Only 0.32 per cent. of the world's water, apparently, is where trees and man can reach and use it. Desalination of sea-water seems a partial solution and the authors have interesting figures and comments on this possibility. Their plea for the preservation of wetlands throughout the world will find a ready response among readers of this journal, and they present an interesting argument for the "farming" of native ungulates in the semi-arid high country of Africa in place of cattle, not merely on the grounds of selective grazing but because they require only about a twentieth as much water as the domesticated breeds. The chapter "Dead Water", which discusses pollution of rivers with synthetic chemicals and industrial effluents, inevitably brings to mind "Silent Spring", and indeed the present book presents a warning as solemn as that of Rachael Carson's classic. It would be reassuring to think that it would stir public conscience as much as hers did.

JOHN CLECC.

\title{
Biogeography and Ecology in Antarctica, edited by J. Van Mieghem and P. Van Oye. Dr. W. Junk, The Hague, E11 10 s.
}

This is the third in a series of publications devoted to the biogeography and ecology of the Southern Hemisphere, the first two having dealt with Australia and southern Africa. It is a composite work, with 18 authors summarising in 762 pages the present state of knowledge of subjects ranging from geology and geomorphology to such specialised fie'ds as the Chaetognaths of the southern oceans and Antarctic Bryozoa. It would need a panel of experts of the competence of the authors to review the details of each chapter critically, but a more general appraisal may be attempted. Such articles as the 72-page review of Antarctic geology by H. J. Harrington and the 67-page account by N. M. Wace of the vascular piants known from the Antarctic will remain as standard references for a good many years, but others are of lesser importance, at least for the general naturalist. Nearly all are written for the specialist, but one of the cxceptions, of interest to anyone with some general knowledge of birds, is the 40-page chapter on Antarctic birds by $\mathbf{K}$. H. Voous. For conservationists the selection of subjects is disappointing, as there is no article on either seals or cetaceans; nor in fact is there any particular mention of the need for conservation in the Antarctic, which is outside the scope of the work.

The general impression is of much detailed infiormation, mainly recently collected, from which relatively few interesting general conclusions can as yet be drawn. This is perhaps inevitable, since the study of the Antarctic fauna and flora is very much in the collecting stage, as it was on other continents a hundred years ago, though it will certainly pass rapidly. Problems of biogeography are often most intractable, since the evidence is often scanty and hard to interpret. Thus in spite of great increases in knowledge of past and present plant distributions round the southern pole, the old problem of the significance of the disjunot distribution of the southern beech Nothofagus in Australasia and South America is still as debatable as it was when Darwin and Hooker discussed it a century ago.

English readers must always be pleased and flattered when their language is chosen for works of international scope, and must admire foreign soientists' command of our language, but many minor mistakes of vocabulary and spelling would have been avoided in two of the chapters if they had been submitted to an English reader before publication. However, th is does not detract from the book's importance as a major reference work on the least known of the six continents.

D. W. SNOW. 